\title{
Succesive vaginal birth after caesarean section: an increasing possibility
}

\begin{abstract}
Vaginal birth after one caesarean section (VBAC) should be encouraged to decrease the rising trend of overall caesarean section rates. VBAC results in overall lesser maternal and neonatal morbidity which overall results in lesser economic burden to the country. In recent years there has been a reported decline in the incidence of VBAC due to dreaded complication of scar dehiscence, uterine rupture and associated professional liability. Presently we document a case of previous one lower segment caesarean section conducted seven years ago followed by four successive uneventful VBAC. Many factors predict the success of VBAC, but past history of VBAC is one of the most powerful predictors as highlighted in the study done by Sinha and the success rate of VBAC varies from institution to institution. The studies pertaining to the maximum number of successive VBAC are sparse in number. Hence, further reporting of such cases should be encouraged so as to impart better family planning services.
\end{abstract}

Keywords: vaginal birth after caesarean section, trial of labor after caesarean section
Volume 3 Issue 3 - 2017

\author{
Mayuri Ahuja,' Neerja Goel, ${ }^{2}$ Shehla Jhamal, ${ }^{3}$ \\ Sweety Malik ${ }^{4}$ \\ 'Senior resident, Department of Obstetrics and Gynecology, \\ Sharda University, India \\ ${ }^{2}$ Professor, Department of Obstetrics and Gynecology, Sharda \\ University, India \\ ${ }^{3}$ Assistant Professor, Department of Obstetrics and Gynecology, \\ Sharda University, India \\ ${ }^{4}$ Senior resident Department of Obstetrics and Gynecology, \\ Sharda University, India
}

\begin{abstract}
Correspondence: Mayuri Ahuja, Senior resident, Department of Obstetrics and Gynecology, Sharda University, Flat no 203, old staff quarters, sharda campus, knowledge park 3, Greater Noida, Uttar Pradesh, 20130, India, Tel 9911017188,

Email soniaahuji@rediffmail.com
\end{abstract}

Received: November 22, 2017 | Published: December 13, 2017
Abbreviations: VBAC, vaginal birth after caesarean section; TOLAC, trial of labor after caesarean section; LSCS, lower segment caesarean section; NSV, non-scalpel vasectomy

\section{Introduction}

Vaginal birth after previous caesarean section (VBAC) should be encouraged to decrease the rising trend of cesarean section rate. The success rate of vaginal birth after caesarean section varies from institution to institution and is general around 60 to $70 \%$. In recent years there has been a reported decline in the rate of VBAC all over the world. Offering VBAC becomes a challenging decision for the obstetrician due to dreaded complication of scar dehiscence, scar rupture and associated medicolegal litigations. Hence, the necessity to determine factors for the prediction of success of trial of labor after caesarean section (TOLAC). Many studies have suggested the importance of past history of successful VBAC as one of the most powerful factors predicting the success of TOLAC but the data as to the maximum no of successive VBAC reported are sparse. With the reporting of this case we will highlight the maximum no of successive VBAC reported in the literature and the controversy surrounding these successive VBAC so as to promote this mode of delivery and to offer better family planning practices.

\section{Case report}

A 30-year-old gravida 5, para 4, living 4, with previous one LSCS and history of 3 successful VBAC presented at term pregnancy in advanced labor to the causality department of School of Medical Sciences and Research (SMS \&R), Greater Noida for further management. She was unbooked and uninvestigated. Her past cycles were regular and according to the patient she had completed nine months of her pregnancy. Her obstetric history revealed P1: Full term LSCS (female), done 9years ago in view of non-progress of labor at SMS \&R. P2: She delivered her second girl child via VBAC at SMS\&R 7years ago. It was followed by laparoscopic ligation, but due to ligation failure resulted in her third pregnancy. As her pregnancy was diagnosed in late second trimester she continued her pregnancy and delivered a full-term male via second successful VBAC, 5years back at SMS \& R. Patient was again advised sterilization but she was lost to follow up. She again delivered her fourth female child via third VBAC 3years back conducted at a remote district hospital. Onset of labor was spontaneous and patient presentation in advanced stage in labor in all her previous VBAC "s. There was no history of augmentation and no documented intrapartum and postpartum complications. Examination at the time of admission showed slight pallor, pulse -96per minute, blood pressure $100 / 60 \mathrm{mmHg}$. Respiratory and cardiovascular system was normal. On per abdominal examination uterus was term size, uterine contour was maintained, good uterine contractions were present, cephalic presentation, FHS-140/min, head 1/5 palpable, no scar tenderness present. On per vaginal examination patient was fully dilated and effaced, membrane absent, head at 0station, pelvis was adequate. Although patient was in modified Robson criteria $5 \mathrm{a}$, decision for vaginal delivery was taken and patient delivered a healthy female child of $2.56 \mathrm{~kg}$ via fourth successful VBAC. There were no intrapartum and postpartum complications. Patient was put on intravenous antibiotics for 72 hours and was advised interval sterilization/Non-scalpel vasectomy on discharge. Husband opted for NSV.

\section{Discussion}

The most important cause of increased caesarean section rate is repeat elective caesarean. With the increasing caesarean section rate across the globe the need to encourage vaginal birth after caesarean section (VBAC) is of utmost importance hence to determine the factors determining the success of TOLAC is of utmost importance. Maternal and fetal factors that influence the success of TOLAC are 
maternal age and pelvis, BMI, interconceptional interval, indication of previous LSCS, BISHOP score, type of onset of labor, fetal weight and the gestational age. Past history of VBAC has been documented as the most important prognostic factor in determining the success of TOLAC as is evident from the studies illustrated below (Tables 1-3).

Past history of VBAC is one of the most powerful factors predicting the success of TOLAC in comparison to vaginal birth prior to LSCS. Past history of VBAC and their relation to success rate of TOLAC have been studied with four successive VBAC only. With increasing no of VBAC various studies suggest that success rate of successive TOLAC rises and at one stage somewhat platues (Figure 1). The success rate of TOLAC after second, third and fourth VBAC is $(90 \%, 90.6 \%$, and $91.6 \%)$ There is scanty data comparing the incidence of scar rupture and successive VBAC yet the need for intensive monitoring during TOLAC cannot be underestimated. With possibility of these increasing successive VBAC, the need to encourage them at one junction needs to be emphasized so as to decrease the rising trend of cesarean section rate and at the same time impart such patients better family planning services as they are also potential candidates for higher birth order.

Table I Studies showing comparison of Success rate of TOLAC (History of VBACVs No history of VBAC)

\begin{tabular}{llll}
\hline Sr. no. & Author & Success rate with(History of VBAC) & Success rate with(No history of VBAC) \\
\hline I & Caughey et al. & $92.80 \%$ & $70.10 \%$ \\
2 & lyer S et al. ${ }^{2}$ & $84 \%$ & $62.10 \%$ \\
3 & BrillY et al. $^{3}$ & $92.80 \%$ & $70.10 \%$ \\
4 & Gyami C et al. & $87.80 \%$ & $75.60 \%$ \\
5 & Hedler et al. & & $81.80 \%$ \\
6 & Haresh et al. & $63.10 \%$ & $62.70 \%$ \\
7 & Lakshmi et al. & $76 \%$ & $41 \%$ \\
8 & Sarita et al. & $87.80 \%$ & $63.30 \%$ \\
\hline
\end{tabular}

Table 2 Studies showing the comparison of success rate of TOLAC (History of vaginal birth before Caesarean Vs History of VBAC)

\begin{tabular}{llll}
\hline Sr. no. & Author & $\begin{array}{l}\text { Success rate(History of vaginal } \\
\text { birth before caesarean section) }\end{array}$ & Success rate(History of VBAC) \\
\hline I & Doshi H et al. ${ }^{\prime}$ & $7 \%$ & $12 \%$ \\
2 & Caughey et al. ${ }^{10}$ & $85 \%$ & $93 \%$ \\
3 & Archana et al." & $39.30 \%$ & $60.70 \%$ \\
\hline
\end{tabular}

Table 3 Studies on the comparison of uterine scar rupture rates with successive VBAC

\begin{tabular}{llll}
\hline Sr. no. & Author & $\begin{array}{l}\text { Scar rupture rates } \\
\text { (No history of }\end{array}$ & $\begin{array}{l}\text { Scar rupture rates (Successive VBAC } \\
(\mathbf{I}, \mathbf{2 , 3}, \mathbf{4})\end{array}$ \\
\hline $\mathrm{I}$ & Zelop et al. ${ }^{12}$ & $1.10 \%$ & $0.20 \%$ \\
3 & Hedler et al. & $5.30 \%$ & $21.80 \%$ \\
4 & Mercer et al." & $0.8 \%$ & $0.45 \% \mathrm{vs}, 0.38 \% \mathrm{vs} 0.54 \%$ vs $0.0 .52 \%$ \\
5 & Krispin et al. & $1.60 \%$ & $0.70 \%$ \\
\hline
\end{tabular}

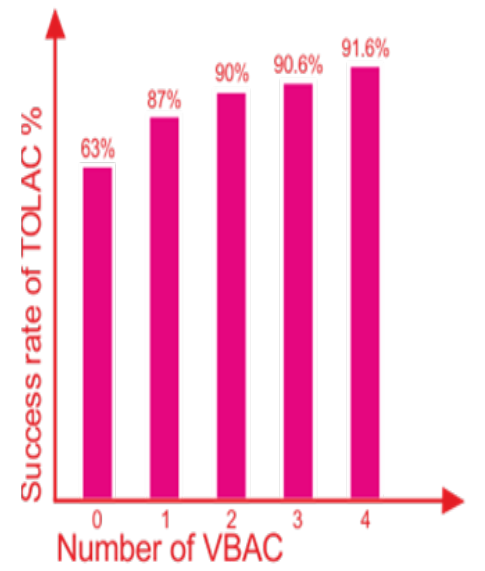

Figure I Success rate of TOLAC with successive VBAC ${ }^{8,1}$

\section{Acknowledgements}

I am thankful to Dr. Neerja Goel, my source of constant encouragement for writing this case report.

\section{Conflict of interest}

There are no financial disclosures of interest.

\section{References}

1. Caughey A, Shipp T, Repke J, et al. Trial of labour after caesarean delivery: The effect of previous vaginal delivery. Am J Obstet Gynecol. 1998;179(4):938-981.

2. Iyer S, Handa P, Basu B. Delivery after one previous caesarean section one-year prospective study. J Obstet Gynecol. 2001;51(2):51-54. 
3. Brill Y, Windrim R. Vaginal birth after caesarean section: review of antenatal predictors of success: J Obstet Gynecol Can. 2003;25(4):275-286.

4. Gyami C, Juhasz G, Gyami P. Increased success of trial of labor after previous vaginal birth after caesarean section. Obstet Gynecol. 2004; 104:715-719.

5. Hedler I, Bujoid E. Effect of prior vaginal delivery or prior vaginal birth after cesarean delivery on obstetrics outcomes in women undergoing trial of labor. Obstet Gynecol. 2004;104(2):273-277.

6. Haresh U, Rohit J. Prognostic factors for successful vaginal birth after cesarean section-Analysis of 162 cases. J Obstet Gynecol of India. 2010;60(6):498-502.

7. Lakshmi B, Pooja R, Ramakone M. Pregnancy outcome in women with previous one cesarean section. J Clin Diagn Res. 2014;8(2):99-102.

8. Sarita S, Devendra K. Clinical evaluation of factors to predict successful vaginal birth after VBAC in cases of previous LSCS. IOSR Journal of Dental and Medical Sciences. 2017;16(3):79-82.
9. Doshi H, Jain R. Prognostic factors for successful vaginal birth after caesarean section. Analysis of 162 cases. J Obstet Gynecol India. 2010;60(6):498-502.

10. Archana M, Ankita M. Study of factors associated with success of vaginal birth after previous one caesarean section. Scholar J of Medical Scieces. 2016;4(1c):210-213.

11. Mercer B, Gilbert S, Landon M, et al. Labor outcomes with increasing number of prior vaginal birth.Obstet Gynecol. 2008;111(2 Pt 1):285-291.

12. Zelop C, Shipp T, Repke JT, et al. Effect of previous vaginal delivery on the risk of uterine rupture during a subsequent trial of labor. Am J Obstet Gynecol. 2000;183(5):1184-1186.

13. Krispin E, Hiersch L, Wilk Goldsher Y, et al. Association between prior vaginal birth after cesarean and subsequent labor outcome. J Maternal Fetal Neonatal Med. 2017;27:1-7. 